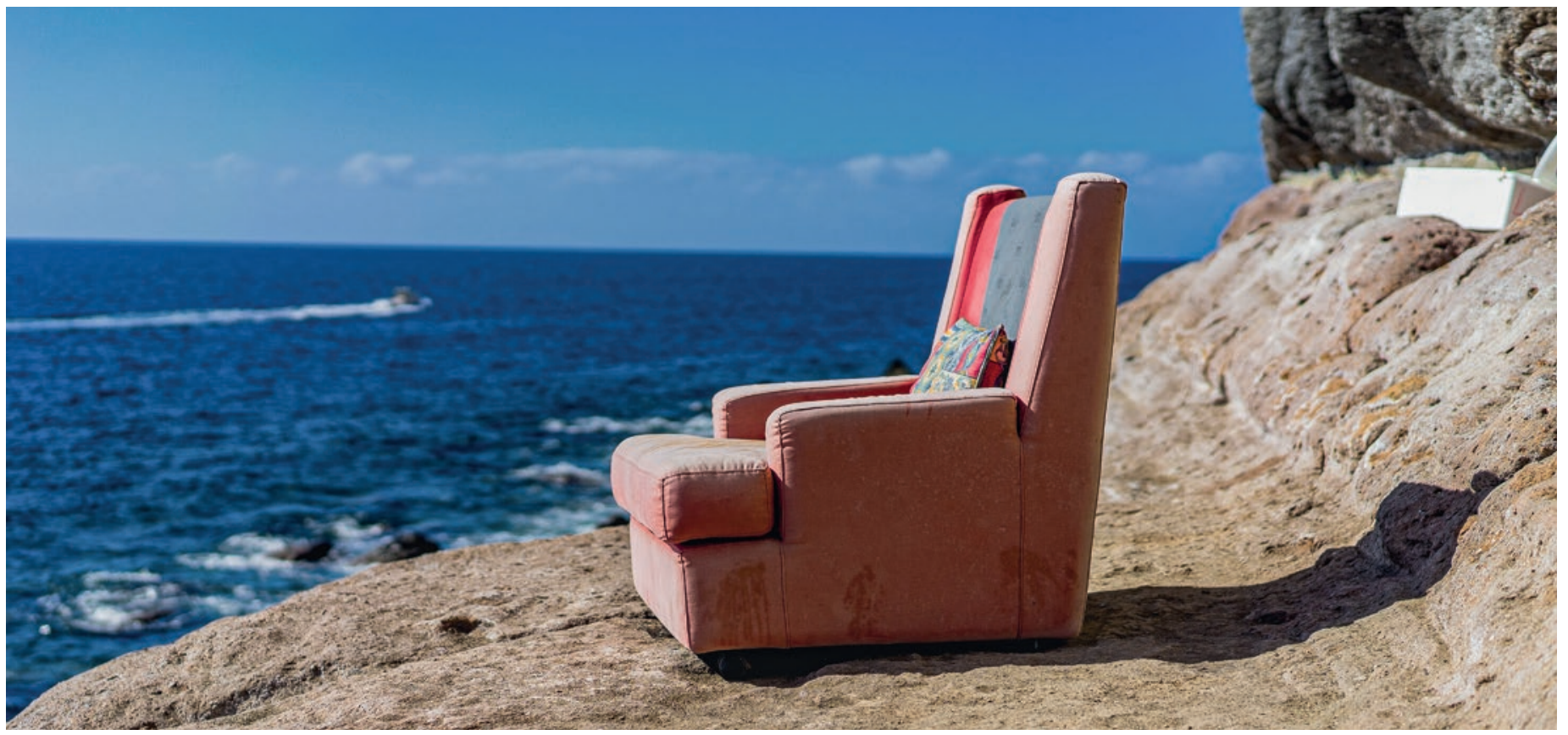

\title{
Deutsch und deutlich
}

\section{Jann Schwarzenbach}

Dr. med., Facharzt für Allgemeinmedizin, Mitglied FMH

Die besinnlichen und mystischen Aspekte des antiken Otiums, des Nichtstuns also, sind einer frenetischen Freizeitnutzung zum Opfer gefallen. Möglicherweise fördert das inquisitorische Wortverbote und trendige Symbolakrobatinnen und Symbolakrobaten.

Vor gar nicht allzu langer Zeit hat mich die Putzfrau im Stich gelassen. Das geschah wohl kaum aus Protest gegen ihre obsolet gewordene Berufsbezeichnung. Dennoch richtete sich meine begriffspolitische Unkorrektheit schlussendlich gegen mich selbst: Ich fasste Eimer und Besen und avancierte zum Putzmann. Für einen Gefreiten der Schweizer Armee war das natürlich kein echter Notfall, und ich hätte die Geschichte längst vergessen, wenn da nicht dieser unwiderstehlich einladende Fauteuil gewesen wäre. So einer mit herrlich weichen Polstern - eine wahre Labsal für ungewöhnlich beanspruchte Gliedmassen. Hier spürte ich denn auch bald einmal nur noch eine unendliche Ruhe, ein wunschloses Wohlgefühl, einfach da zu sein.

Ob Tagtraum, Glückshormone oder Endorphine - wer will das wissen. Es war so göttlich: kein geschäftiges Hin und Her, kein ungeduldiges Stühlerücken aus dem Wartezimmer, der Computer im Halbschlaf und selbst das aufsässige Telefon stummgeschaltet. Ein Praxisbetrieb im Ruhemodus - Otium statt Negotium. Die Menschen der Antike schätzten solche Auszeiten zur geistigen Einkehr bei sich selbst. Heutzutage allerdings ist das besinnliche Nichtstun einer fragwürdigen Intensivnutzung der Freizeit zum Opfer gefallen. Einschlägige Selbstfindungskurse und Alternativurlaube versuchen hier etwas Gegensteuer zu geben, werden aber dem antiken Müssiggang nur teilweise gerecht. Letzterer erschöpfte sich nämlich nicht im Tschüss an die Hektik der Welt. Er umfasste ein zusätzliches Herunterfahren allen Wollens, Suchens und Räsonierens. So entrümpelte man das eigene Bewusstsein und schuf Platz für neue und andersartige Erfahrungen.

\section{Ein Flirt mit dem Nichts}

Diese bewusstseinserweiternde Dimension des Otiums wurde später zum erleuchtenden Tummelplatz mys- 
tisch angehauchter Geister. Hier ging's dann um rituelle Ekstasen, ums Eins-Werden auf Zeit mit dem geheimnisvollen Urgrund aller Schöpfung. Die so ersehnte Gottesnähe erreichte man nur mit der Premium-Version besinnlicher Auszeiten: einer totalen seelischen Funkstille - einem abgründigen Flirt mit dem Nichts.

Es war so göttlich: kein geschäftiges Hin und Her, der Computer im Halbschlaf und selbst das aufsässige Telefon stummgeschaltet.

Genaueres zu solchen psychischen Ausnahmezuständen wollte damals keiner verraten, immer nach dem Motto: «Si comprehendis non est Deus.» - «Wenn du's verstehst, ist's nicht mehr göttlich.»

\section{Ein Tool göttlicher Software}

Ganz ähnlich dachte auch der Dominikanermönch Eckhart von Hochheim (1260-1328). Der als Meister Eckhart berühmt gewordene Mystiker wurde nämlich niemals müde, alle Versuche anzuprangern, Gott verstandesmässig festzuhalten. Dieser sei das begrifflich völlig Negative, der unergründliche Gegenpol zu aller Kreation. Nicht nur im metaphysischen, sondern auch im ethischen Bereich liess der blitzgescheite Theologe seine Stimme hören. Mit ungewohnter Schärfe entlarvte er das Selbstinteresse, das hinter Gebet und Rechthaberei des klerikalen Gutmenschentums steht. Für ihn gab es keine Moral nach menschlichem Rezept: Richtiges Handeln sei nicht Sache der abwägenden Vernunft, sondern Ausdruck eines geheimnisvollen "Fünkleins» - eines Tools göttlicher Software in den Tiefen unserer Seele.

\section{Ein Mystiker spricht Klartext}

Meister Eckhart war aber alles andere als ein Mystiker im Glashaus - er wollte kein Lesemeister, sondern ein Lebemeister sein. Nicht unbedingt mit Besen und Eimer. Dennoch hätte er wahrscheinlich kaum gezögert, wenn nötig, auch Gotteshäuser auszufegen.

\section{Er nannte die Dinge bei ihrem angestammten Namen und wich vom kirchlichen Main- stream ab.}

Nur zum Klinkenputzen beim Vatikan, da war er sich zu schade. Dogmen und Regelwerken stand er nämlich kritisch gegenüber, nannte die Dinge bei ihrem angestammten Namen und predigte so, dass man ihn verstand: auf Deutsch und das auch deutlich. Dabei wich er - mehr in der Form als in der gläubigen Gesinnung - vom kirchlichen Mainstream ab und wollte seine Schäfchen dazu animieren, selbst zu denken und eigene Wege zu beschreiten. Den durchschnittlichen Zuhörerinnen und Zuhörern gefiel das, den klerikalen Machthabern bedeutend weniger. So entfachte er denn auch einen Shitstorm seitens der heiligen Inquisition - der damaligen, religionspolitisch korrekten Intelligenzia.

\section{Sprachakrobatische Leerläufe}

Die Kirche hat - zumindest in den aufgeklärten Demokratien - ihre Macht und ihren Schrecken eingebüsst. Den inquisitorischen Ungeist aber, den gibt es immer noch: in den Köpfen politisch korrekter Wortakrobaten. Putzfrau etwa, oder auch Pharmavertreter - das geht heute gar nicht mehr. Sie sind jetzt Raumpflegerinnen und wissenschaftliche Berater. Diese formalen Upgrades bringen den Veredelten substantiell überhaupt nichts, weder besseren Lohn noch anständigere Zwangspausen im Wartezimmer.

\section{Neologistische Etiketten fallen auf. Das hilft der Diskriminierung und nicht der Emanzipation.}

Und das ist noch nicht alles: Neologistische Etiketten können sogar kontraproduktiv sein. Sie fallen nämlich auf und wirken lächerlich. Das hilft der Diskriminierung und nicht der Emanzipation. Ganz ähnlich verhält es sich auch mit den gendergerechten Symbolzwängereien. Ärztinnen und Ärzte jedenfalls brauchen so etwas nicht. Wir sind seit jeher Kollegen, keiner mehr und keine weniger - mit oder ohne eingeschobenes grosses «I».

Abschliessend stellt sich noch die Frage, wer denn eigentlich für all diese sprachakrobatischen Leerläufe verantwortlich ist. Wie bei einem schlechten Witz ist es schwierig, hier die effektiven Erfinderinnen und Erfinder auszumachen. Vielleicht sind es ja einfach moderne Freizeitnutzende, unterforderte Menschen mit viel überschüssiger Energie, denen Begriffe wie Besinnlichkeit und Bewusstseinserweiterung Fremdwörter geblieben sind. Die mystische Dimension des Otiums offenbart sich uns Normalos halt erst nach getaner, wirklicher Arbeit. Wer will, darf das gerne beim Praxisputzen ausprobieren. Für Mitglieder der FMH gibt es allerdings eine weniger schweisstreibende $\mathrm{Al}$ ternative: die allwöchentlichen «Horizonte» in ihrem «Gelben Heft».

Bildnachweis

Dan Gold / Unsplash 